\title{
The Relationship between Mistakes and Feedbacks Encountered in Mathematics Course in the 7th Grade
}

\author{
Ali TÜRKDOĞAN 1 * (D) Adnan BAKİ 2 (D) \\ ${ }^{1}$ Sivas Cumhuriyet University, Faculty of Education, Sivas, Turkey, aliturkdogan@hotmail.com \\ ${ }^{2}$ Trabzon University, Fatih Faculty of Education, Trabzon Turkey, adnanbaki@gmail.com \\ * Corresponding Author: aliturkdogan@hotmail.com
}

\begin{tabular}{|c|c|}
\hline Article Info & Abstract \\
\hline $\begin{array}{l}\text { Keywords: Teaching mathematics, } \\
\text { mistake, mistake types, mistake- } \\
\text { feedback relationship, teacher's } \\
\text { guidance } \\
\text { doi) } 10.18009 \text { /jcer.856700 } \\
\text { Publication Language: English }\end{array}$ & $\begin{array}{l}\text { Perhaps the biggest obstacles to the effective implementation of the } \\
\text { student-centred mathematics programs are mistakes. So it is very } \\
\text { important to know that not every mistake is the same and that the } \\
\text { same type of feedback cannot be used in every mistake type. In this } \\
\text { study, firstly } 870 \text { mistakes and feedback encountered by } 4 \text { teachers } \\
\text { in } 120 \text { hours were analysed. Then, which feedback technique was } \\
\text { used in which type of mistake according to Türkdoğan's } \\
\text { clarification and discussed to what degree the feedback met the } \\
\text { expectations of student-centred mathematics curricula. It was found } \\
\text { that the use of the Ignoring the Mistake or Accepting it as Correct, } \\
\text { Saying the True Answer and Saying the Answer is Wrong feedback } \\
\text { techniques in the first type of mistake was more appropriate. The } \\
\text { use of Creating Conflicts, Simplifying or Making Connections } \\
\text { feedback techniques was insufficient. It is thought that organizing } \\
\text { educational activities for teachers and teacher students about } \\
\text { mistakes and feedbacks will be useful to establish a more effective } \\
\text { student-centred environment. }\end{array}$ \\
\hline open 0 access $\bigcirc$ CrossMark & $\begin{array}{l}\text { To cite this article: Türkdoğan, A. \& Baki, A. (2021). The } \\
\text { relationship between mistakes and feedbacks encountered in } \\
\text { mathematics course in the } 7 \text { th grade. Journal of Computer and } \\
\text { Education Research, } 9 \text { (17), } 480-496 \text {. DOI: } 10.18009 / \text { jcer. } 856700\end{array}$ \\
\hline
\end{tabular}

\section{Introduction}

Some concepts need to be re-examined for student-centred education to be successful. One of these concepts is the concept of "mistake" (Santagata, 2002; Türkdoğan, Baki \& Çepni, 2009). In behavioural theories, the mistake was considered the product of student carelessness and (or) a deficiency and inability in material, teacher or communication path (Santagata, 2002; Türkdoğan et. al., 2009). In other words, according to the behaviourist approach, it is not necessary for the mistake to be revealed, discussed, and there is no contribution and need for it to be seen by other students. The understanding of ignoring seen in the behaviourist approach has changed with cognitive theories. In this sense, cognitive approaches have divided the meaning of mistake into two; misconceptions and mistake or error. However, it is also known that cognitive approaches attribute importance to the 
detection and elimination of misconceptions. However, it is seen that the mistakes that are not misconceptions are ignored. In this context, it is useful to state that understanding and thinking the mistake with the terminology related to the misconception, which is a special form of mistake, will make it difficult for us to understand the mistake and the feedback given to it (Türkdoğan et. al., 2009).

Constructivist approach accepts that the emergence of mistake in the learning environment is a natural phenomenon. For this reason, it argues that the learning environment should be analysed well and that scientific knowledge should be reached through mistakes by accepting mistakes as an opportunity to learn (Heinze, 2005). In this sense, the mistake and the feedback given to the mistake have contributed to the learning environment. Some of these contributions are:

1) It shows that cognitive disequilibrium occurs in the student, that is, that learning is taking place.

2) It is an indicator that the students are on the verge of learning that the activity is dealing with a learning activity appropriate to the knowledge level of the students.

3) Mistakes contribute to the preparation of the lesson plan in other classes more effectively by providing an understanding of the issues that are not understood

4) Mistakes allow the teacher to identify and eliminate the weaknesses of teaching activities.

5) It positively affects the attitudes of students who find the mistakes of their friends in mathematics class.

6) Mistakes contribute to the development of teachers' ability (teaching power) to give feedback to mathematical mistakes.

7) Teachers examine the character of students ' mistakes and get an idea of when they can promise their students. Thus, mistakes allow for both process assessment and the creation of effective learning environments (Heinze, 2005; Santagata, 2000).

As can be understood from these items, it is seen that effective feedback has an important place in student-centred learning. Piaget points out that when the student makes a mistake, the answer should not be said to him/her directly, and saying that his/her answer is wrong will also negatively affect the student's thinking about the event and participation 
in the activity. Piaget proposes to give feedback to the student by asking additional questions and making modelling so that the student can realize his/her mistake (Bybee \& Sound, 1990).

Another point of view about the feedback given to the mistake can be obtained from Vygotsky's perspective on learning, another precursor of the constructivist approach. Vygotsky states that an expert should assist students who fail a task (such as problemsolving or performing activities). This expert could be a teacher or a peer. It even states that a student can learn better from his/her peers due to the nature of the language they use (Vygotsky, 1986). In addition, researcher is determined that the student, at the border of learning threshold (Zone of proximal development), will need guidance in learning. In this sense, collaboration (student receives feedback during the collaboration) is important for learning and student development (Vygotsky, 1978, 1986; Wood, Bruner \& Ross, 1976).

Carrying out studies on mistake and feedback given to mistake will contribute to both teachers, students and creating effective learning environments. The necessity to research mistake and feedback given to mistake is not only due to the benefits of mistake, but also student-centred education (Santagata, 2002; Türkdoğan, 2011) and mathematics (Türkdoğan, 2011) has a structure suitable for mistakes. The student-centred education structure creates an environment suitable for mistakes. Student-centred curricula are mainly based on the 5E model, and in each phase of the 5E model, the students -who are not an information authority-, are involved in activities in some way (Türkdoğan, 2011). This model, like other models, includes the introduction (Engage), process (Explore, Explain, Elaborate) and evaluation phases. While the introduction and evaluation phase mainly points to misconceptions, the process phase points to mistakes. In addition, the role of the teacher in student-centred education is defined as the person guiding learning (Türkdoğan, 2006; Türkdoğan et. al., 2009). For this reason, in order for the teacher to guide learning, mistakes must be understood better, and in order to understand the mistake better, the feedbacks given to the mistakes as a step must be understood well by teachers (Türkdoğan, 2006; Türkdoğan et. al., 2009). It is not considered very likely to distinguish between the mistake and feedback given to mistake.

Mathematical knowledge is taught by associating (adapting) with the previous concept, subject or unit and the subjects of the past years within the framework of the spiral and cumulative structure. This situation leads to the expansion of the meaning of many 
concepts. Students who ignore these expansions of meaning can make mistakes. Besides, mathematics is a field of study consisting of concepts, the majority of which are abstract. This spiral and abstract structure make it necessary to structure a concept by associating it with many concepts. Many problems may arise during the associating of information with other information, that is, the creation of schemas. However, it is difficult to understand how an individual constructs information through what processes and to understand the current forms of configuration (Baki, 2008). Therefore, it is natural that the process of understanding mathematics and associating abstract structures with each other is often interrupted by mistakes. Sharing with teachers and teacher candidates that it is natural for students to make mistakes is important for them to create effective learning environments (Nordstrom, Wendland \& Williams, 1989). In summary, the structure of mathematics and the nature of the student-centred curriculum points out the necessity of studies related to mistake and feedback given to mistake.

When the studies related to the mistake are examined, some studies that are required to be summarized especially for this study are as follows:

In their study, Sterponi and Santagata (2000) examined the question of whether teaching is a social activity with the "mistake" dimension. For this purpose, the feedback given by the Italian and American teachers to the student who made a mistake in the math class and the feedback given by the American and Italian families to the brother/sister who made the mistake at the dining table were examined. It was determined that the feedbacks given to the mistake differed between cultures (countries), while they were similar within the country (at the school-dining table). It has been found that American families and teachers prefer to give feedback to the mistake by reassuring, not directly criticizing it and starting from a positive aspect, and that Italian families and teachers have given feedback to the mistake by distrustful and directly criticizing it. The researchers considered this situation as a factor proving the idea that teaching is a cultural element. The idea that "teachers, as members of that society, carry mistake management sequence techniques to schools" was discussed in the study. In addition, in the study, although the same curriculum is not applied in every school in the USA, the emphasis on the cultural dimension of the feedback given to the mistake was further strengthened by drawing attention to the dimension of giving feedback to the students with the same understanding of giving feedback. 
In Santagata's (2002) doctoral thesis, he classified mathematical mistakes and the first feedbacks used by teachers. In the study, the mistake and the feedback given to the mistake was discussed as a sociological phenomenon. The researcher has classified the feedback given to the mistake in under three headings, taking into account the student's selfconfidence, and in order to make this classification, he has addressed many concepts such as feedback techniques related to the mistake and types of mistake.

In the study, which stated that there was no study about the mistake in the real classroom environment, the course studies of the 30 Italian and 30 American mathematics teachers in the eighth grade were examined from the video recordings. The researcher has examined the feedback given by the teachers to the students who have made the mistake, stated that the mistake can be best interpreted from a cultural perspective and defined the process of giving feedback to the mistake firstly in order to examine the dimensions of the course functioning, the percentages of the mistake etc. depending on the countries.

In the study, the mistake types are classified under 10 headings. In this classification, mistakes are handle in the dimension of self-confidence by taking into account the words, the tone of voice or the mimics used by the teacher. In the study, mistake types, feedback techniques and social classification were made first and then the basic questions of the research were investigated. The study also compared Italian course functioning with American course functioning. The researcher has many studies based on these basic assumptions and definitions and comparing the feedback given to the mistakes with the situation in different countries especially with the dimension of self-confidence (Sterponi \& Santagata, 2000). It is understood from these studies that the mistakes and the feedback given to the mistakes are more appropriate to be carried out considering a classification prepared in accordance with that culture.

Some other studies related to the mistake were carried out by computerists. These studies, which are stated the mistake and making a mistake is a natural process and can be learned from the mistake, were carried out with teachers and teacher candidates. In these studies, it was found that making a mistake was natural, the learning environment in the specified groups was more student-centred (students talked, expressed ideas, etc.) and student-student, student-teacher interaction was higher (Nordstrom, Wendland \& Williams, 1989). For this reason, it is thought that teachers' perceptions of mistake should be 
determined and arranged in accordance with the expectations of student-centred education understanding.

It is necessary to investigate how the mistake and the feedback given to the mistake is perceived and how different it is in Turkish school culture. It is thought that these researches will provide both a better understanding of mistake and the feedback given to the mistake in the Turkish education system and a better understanding and development of the mistake and the perspective of a mistake by comparing them with their international counterparts. For this reason, the distribution of the relationship between the mistakes encountered in the Turkish education system and the types of feedback given to the mistakes should be examined. Thus, it will be possible to determine which feedback techniques are used more for which type of mistake and to discuss which feedback types are more ideal for which type of mistake within the scope of student-centred education. In addition, it is thought that it may be possible to create infrastructure for the development of the teaching content at the undergraduate level, which is necessary for the training of teachers who are confident and able to give feedback that is more effective.

In the scope of this study, mistake types and feedback types classification developed by Türkdoğan (2011) will be used. Author classified the mistakes under 4 headings by taking into account the need to redefine the mistake in accordance with student-centred educational needs: 1) Mistakes Regarding Scientific Language 2) Mistakes Regarding the Use of Process and Strategy 3) Mistakes Regarding Induction-Deduction 4) Mistakes Regarding Classifications (Türkdoğan, 2011; Türkdoğan \& Baki, 2013). He also identified the feedbacks used by teachers and classified them under 6 main headings: 1) Ignoring the Mistake or Accepting it as Correct 2) Saying the True Answer 3) Saying the Answer is Wrong 4) Creating Conflicts 5) Simplifying 6) Making Connections (Türkdoğan, 2011; Türkdoğan \& Baki, 2012).

\section{Method}

This study was conducted in the fall semester of 2008-2009 academic years with four $7^{\text {th }}$ grade mathematics teachers in the context of the case study method (Table 1). The data of the study was obtained by the unstructured observation. In this context, each teacher was observed for 30 hours in total for 120 hours and the observations were noted directly in the observation notebook. Within the scope of this study, only the first feedback given by teachers to the mistake was examined. Observed lessons are synchronous. That is, it was 
observed while teachers were handling the same subjects. For this purpose, the data in the observation notebook was analysed by descriptive analysis method under the classification of researcher Türkdoğan (2011) regarding the mistake types and feedback techniques and then converted into a table (Table 2). During the discussions, the notes taken during the observations were also used.

Table 1. Some information about the sample group of the study

\begin{tabular}{|c|c|c|c|c|c|c|}
\hline Profession & Year & Branch & Age & $\begin{array}{l}\text { Graduation } \\
\text { Department }\end{array}$ & University & Other Information \\
\hline 1. Teacher & 9 & $\begin{array}{l}\text { Primary } \\
\text { Mathematics } \\
\text { Teacher }\end{array}$ & 32 & $\begin{array}{l}\text { Department } \\
\text { of } \\
\text { Mathematics } \\
\text { at the Faculty } \\
\text { of Education }\end{array}$ & $\begin{array}{l}19 \quad \text { May } \\
\text { University }\end{array}$ & \\
\hline 2. Teacher & 8 & $\begin{array}{l}\text { Primary } \\
\text { Mathematics } \\
\text { Teacher }\end{array}$ & 32 & $\begin{array}{l}\text { Department } \\
\text { of Elementary } \\
\text { Mathematics } \\
\text { Teaching }\end{array}$ & $\begin{array}{ll}\text { Karadeniz } & \\
\text { Technical } & \\
\text { University } \\
\text { Faculty of } \\
\text { Fatih } \\
\text { Education }\end{array}$ & $\begin{array}{l}\text { He/she worked as a } \\
\text { high school teacher in } \\
\text { rural district in } \\
\text { another province for } 4 \\
\text { years. }\end{array}$ \\
\hline 3. Teacher & 6 & $\begin{array}{l}\text { Primary } \\
\text { Mathematics } \\
\text { Teacher }\end{array}$ & 29 & $\begin{array}{l}\text { Department } \\
\text { of Elementary } \\
\text { Mathematics } \\
\text { Teaching }\end{array}$ & $\begin{array}{l}\text { Atatürk } \\
\text { University } \\
\text { Kazım } \\
\text { Karabekir } \\
\text { Faculty of } \\
\text { Education }\end{array}$ & $\begin{array}{l}\text { He/she worked for } 2 \\
\text { years in high school, } 2 \\
\text { years in a primary } \\
\text { school in the village, } \\
\text { and for the last } 2 \\
\text { years, he/she worked } \\
\text { in a primary school } \\
\text { where data was } \\
\text { collected. }\end{array}$ \\
\hline 4. Teacher & 4,5 & $\begin{array}{l}\text { Primary } \\
\text { Mathematics } \\
\text { Teacher }\end{array}$ & 27 & $\begin{array}{l}\text { Department } \\
\text { of Elementary } \\
\text { Mathematics } \\
\text { Teaching }\end{array}$ & $\begin{array}{l}\text { Gazi } \\
\text { University } \\
\text { Faculty of } \\
\text { Education }\end{array}$ & $\begin{array}{l}\text { He/she worked as a } \\
\text { primary mathematics } \\
\text { teacher at a school } \\
\text { close to the centre in } \\
\text { another province for } \\
3.5 \text { years and for the } \\
\text { last } 1 \text { year, he/she } \\
\text { worked at the school } \\
\text { where data was } \\
\text { collected. }\end{array}$ \\
\hline
\end{tabular}

Within the scope of this study, the question of whether the mistakes faced by the teachers and the feedback given to the mistakes have changed depending on the teachers will not be answered. Therefore, only the number of mistakes faced by each teacher will be given, but the mistake types and distributions of feedback techniques will not be given according to the teachers. Thus, it will be possible to carry out the main discussion of the 
study on mistakes and feedbacks. In order to understand the discussions in the study, code and super codes related to the mistake types and feedback techniques could be seen at the another studies of the authors (Türkdoğan, 2011; Türkdoğan \& Baki, 2012, 2013).

\section{Finding and Discussion}

In the first teacher's course, the researcher was able to identify 252 (an average of 8.40 mistakes per course) mistakes. In the second teacher's course, the researcher was able to identify 290 (an average of 9.67 mistakes per course) mistakes. In the third teacher's course, the researcher was able to identify 189 (an average of 6.30 mistakes per course) mistakes. In the fourth teacher's course, the researcher was able to identify 139 (an average of 4.70 mistakes per course) mistakes. A total of 870 mistakes identified and the variation of the 870 feedback given to these mistakes depending on the mistakes types are given in Table 2.

Table 2. Relationship between mistake types and feedback techniques

\begin{tabular}{|c|c|c|c|c|c|c|c|c|}
\hline \multirow[b]{2}{*}{ Mistake Type } & & \multicolumn{6}{|c|}{ Feedback Techniques } & \multirow{2}{*}{ Total } \\
\hline & & 1 & 2 & 3 & 4 & 5 & 6 & \\
\hline \multirow{3}{*}{1} & Number & 54 & 128 & 115 & 3 & 6 & 1 & 307 \\
\hline & $\begin{array}{l}\text { Percentage due to mistake } \\
\text { types }\end{array}$ & 17.6 & 41.7 & 37.5 & 1 & 2 & 0.3 & 100 \\
\hline & Total percentage & 6.2 & 14.7 & 13.2 & 0.3 & 0.7 & 0.1 & 35.3 \\
\hline \multirow{3}{*}{2} & Number & 30 & 100 & 107 & 28 & 4 & 0 & 269 \\
\hline & $\begin{array}{l}\text { Percentage due to mistake } \\
\text { types }\end{array}$ & 11.2 & 37.2 & 39.8 & 10.4 & 1.5 & 0 & 100 \\
\hline & Total percentage & 3.4 & 11.5 & 12.3 & 3.2 & 0.5 & 0 & 30.9 \\
\hline \multirow{3}{*}{3} & Number & 23 & 21 & 48 & 13 & 3 & 1 & 109 \\
\hline & $\begin{array}{l}\text { Percentage due to mistake } \\
\text { types }\end{array}$ & 21.1 & 19.3 & 44 & 11.9 & 2.8 & 0.9 & 100 \\
\hline & Total percentage & 2.6 & 2.4 & 5.5 & 1.5 & 0.3 & 0.1 & 12.5 \\
\hline \multirow{3}{*}{4} & Number & 41 & 50 & 69 & 22 & 1 & 2 & 185 \\
\hline & $\begin{array}{l}\text { Percentage due to mistake } \\
\text { types }\end{array}$ & 22.2 & 27 & 37.3 & 11.9 & 0.5 & 1.1 & 100 \\
\hline & Total percentage & 4.7 & 5.7 & 7.9 & 2.5 & 0.1 & 0.2 & 21.3 \\
\hline \multirow{3}{*}{ Total } & Number & 148 & 299 & 399 & 66 & 14 & 4 & 870 \\
\hline & $\begin{array}{l}\text { Percentage due to mistake } \\
\text { types }\end{array}$ & 17 & 34.4 & 39 & 7.6 & 1.6 & 0.5 & 100 \\
\hline & Total percentage & 17 & 34.4 & 39 & 7.6 & 1.6 & 0.5 & 100 \\
\hline
\end{tabular}

When Table 2 is examined, it is observed that 54 (17.6\%) times 'ignore the mistakes', $128(41.7 \%)$ times "saying the true answer", 115 (37.5\%) times saying "the answer is wrong', 
3 times 'creating cognitive conflict' times 'simplification' and one time 'associating' feedback techniques are used for the first type of mistakes.

In the light of these data, it is observed that the feedback techniques such as saying the true answer, saying the answer is wrong, ignoring the mistake, simplifying, creating cognitive disequilibrium and associating are used in the first type of mistakes. In this sense, it can be said that the nature of the first kind of mistakes is more compatible with the nature of the first, second and third feedback techniques. It is known that teachers get angry when students make mistakes in simple tasks such as definitions, terms and symbols, but if they make mistakes in complex tasks, teachers tolerate this situation and make efforts to teach again (Heinze, 2005). In other words, the idea that the feedback given may differ depending on the shape of the mistakes is also stated in the literature.

The first type of mistakes points out the mistakes related to the information that requires remembering such as definition, term, representation and symbol so it is thought that it is difficult to use the fourth, fifth and sixth feedback techniques. Because these feedback techniques are more aimed at making an inference, it is highly unlikely that they will be effective in the creation of information based on acceptance such as definitions, terms or symbols. For example, "How can a teacher whose student says the definition wrong give feedback using a model or simplification?" The difficulty of using these feedback techniques in this mistake type will be seen when the examples are considered.

When the cases of the first mistake type in which the fourth, fifth and sixth feedback technique was used were examined, it was observed that the first mistake type of mistakes belonged to the super code of "mistakes related to vocabulary". Therefore, it is thought that these feedback techniques can be used. In summary, it can be said that the use of first, second and third feedback techniques is appropriate for giving feedback to a mistake of the first type.

When Table 2 is examined, it is observed that 30 (11.2\%) times ignore the mistakes; $100(37.2 \%)$ times saying the true answer, 107 (39.8\%) times saying the answer is wrong, 28 (10.4\%) times creating cognitive disequilibrium and 4 times simplification feedback technique are used for the second type of mistakes. In the second type of mistake, it is observed that the most commonly used feedback techniques are "saying the answer is wrong" and "saying the true answer". There is little difference between the usage rates of these two feedback techniques. It has been observed that the use of "saying the answer is 
wrong" feedback for the second type of mistake, especially in the operational dimension, allows all students to deal with the question for sufficient time. For this reason, it is thought that the use of the "saying the answer is wrong" feedback technique may also be appropriate for the second type of mistake. In order to perform the operations correctly, if there are any definitions or features that the student does not know, they must be reported to the student (giving feedback by saying definition-the rule: super code for saying the answer is wrong). This incomplete information may be in the form of reminding the definition, feature or processing stages. In this respect, the "saying the answer is wrong" feedback technique is also considered a suitable feedback technique for this mistake type, considering observations.

The "saying the true answer" feedback technique is thought to be a necessary feedback technique for the progress of the process. In this sense, this feedback technique can be used frequently especially in the mistakes that occur during the entrance and evaluation stages of the activities. In addition, by nature of mathematics, it requires using many theorems or features to prove another theorem or to solve the problem. Most of the properties are given by making proof, but every time a mistake is made, the proof cannot be made over and over again. For this reason, it is necessary to use the "saying the true answer" feedback technique especially in reminding the process stages. However, the use of "saying the true answer" feedback technique is considered proportionally higher than necessary.

The second type of mistakes is the one that creates the most cognitive disequilibrium. Especially, if the results are different by making a solution with a second method, "creating cognitive disequilibrium" feedback technique comes to the fore in this type of mistake. It is thought that the "creating cognitive disequilibrium" feedback technique is a more appropriate feedback technique for the types of mistakes involving relations between concepts rather than the mistakes made in the process stages or processes. Because it is difficult to create disequilibrium in the mistakes made in information based on mathematical assumptions. It is also difficult for the student to realise his or her mistake as a result of mental processes. It is thought that "Simplification" and especially "Return to simple question" feedback can be effective in eliminating the second type of mistakes. This situation will be compatible with the simple to difficult teaching principle. The "simplifying" feedback form is also a feedback technique that can be used especially in cases where process steps need to be applied. 
It is observed that the sixth feedback technique was never used in the second type of mistake. If there are connections made during the teaching phase-which the first teacher in the study has been observed to make connections from time to time- the connections can be used to correct this mistake when they are made wrong. It has also been observed that making associations with daily life, especially in the field of integers, be useful when students are unable to solve the questions.

When Table 2 is examined, it is observed that 23 (21.1\%) times ignore the mistakes, $21(19.3 \%)$ times saying the true answer, $48(44 \%)$ times saying the answer is wrong, 13 (11.9\%) times creating cognitive disequilibrium, 3 times simplification and one-time associating feedback technique are used for the third type of mistakes.

The third type of mistake is related to generalizations that are frequently emphasized in the general objectives of primary education. It is seen that the simplification feedback technique is used 3 times in the third type of mistake. Generalizations made from several examples are a requirement of the nature of student-centred education. It has also been stated by teachers that wrong generalizations are inevitable when the student is active. In terms of the formation process of generalizations, they are the expressions that are used more for understanding than for remembering, that is, for summarizing and explaining the schemas in the individual's mind. For this reason, it is not wrong to say that the third kind of mistake that most fit the situation that Santagata (2002) describes as a sign of the disequilibrium that occurs in the individual.

In the third type of mistakes, it is seen that "saying the answer is wrong" feedback technique is used most. It is known that although students learn the correct information and keep it in their memories, they also have the misconceptions in their minds and use them where necessary. In this sense, it is important to know whether the generalizations that are made express the misconception of existing concepts or whether the generalizations that are made at that moment. But this is a question that cannot be answered within the scope of this study. In this context, it should be known that if false generalizations are the result of misconceptions, it will not be enough to give feedback to these mistakes by simply saying "wrong".

Using the "saying the answer is wrong" feedback can only suppress mistakes for a short period. This is because the misconceptions can continue to exist even as a result of the methods of eliminating the misconceptions (Bahar, 2002). In this sense, it is thought that 
perhaps the most effective feedback technique in the third type of mistake may be the "creating cognitive disequilibrium" feedback technique. Also, the fact that many techniques that will provide conceptual change are never used by teachers provides important clues in terms of what can be done at the undergraduate level for concept teaching. All four teachers stated that they did not receive any education at the undergraduate level or later regarding the mistake or misconception.

One of the super codes for the third type of mistake is the mistakes made during pattern making. With the student-centred curriculum, the importance of the subject of patterns in mathematics has increased much more than in traditional education. It is known that figure patterns have an important place in understanding the subject of the pattern. The students encounter such patterns and conduct teaching activities starting from the first level of primary education. Therefore, the use of the sixth feedback technique is considered insufficient. It is thought that teachers can easily use the "pattern-making" feedback method and that students can easily understand these feedbacks. However, it has been observed that some teachers make some important mistakes that may create misconceptions in the student in new application subjects, such as patterns. In other words, it is thought that some of the teachers have not yet fully understood the subject of patterns; they may not have been able to give feedback by creating a pattern to the students who have done the mistake. Similarly, it is seen that teachers other than a teacher in the study almost never use associating after teaching. Therefore, it is considered natural to use the "associating" feedback technique for one time in the third type of mistake. It is thought that the use of phasing technique or another simplification strategies for third types of mistakes may not be appropriate. Because giving feedback to a mistake that expresses a general thing with an example or likening it to another generalization may cause many drawbacks. For example, students may think that they can prove by giving a few examples.

When Table 2 is examined, it is observed that 41 (22.2\%) times ignore the mistakes, $50(27.0 \%)$ times saying the answer is wrong, 69 (37.3\%) times saying the true answer, 22 (11.9\%) times creating cognitive disequilibrium, one time simplification and 2 times associating feedback technique are used for the fourth type of mistakes. When the feedbacks given based on the errors are examined, it is seen that the third, second, first, and fourth feedback techniques are used mostly, the fifth feedback technique is used once and the sixth feedback technique is used twice. The fourth type of mistakes refers to the mistakes students 
make when placing a given sample in the appropriate class and the mistakes they make while giving an example.

The fourth kind of mistake is mostly related to examples and classifications of undeniable importance in mathematics. These mistakes are often considered as a sign that there are difficulties in structuring the concepts. When the table is called, a shape appears in everyone's mind. In fact, that shape is the example that best reflects the meaning attributed to the table concept by that person. In this sense, examples are one of the best indicators of the structure of the student's understanding regarding that concept. However, the examples help students to learn the concept and distinguish the concepts from each other, as well as it is one of the most important clues for understanding how the student understands the concept when the examples are given by the student. Therefore, examples are one of the most effective tools to understand how the students construct the concept (s) in their mind and how they establish relationships between concepts. If the given example is wrong, then it will be understood that the concept is constructed incorrectly or that the process is working wrong. In this context, perhaps the most important mistakes in the context of understanding mental processes are the fourth kind of mistakes.

Another form of the fourth type of mistakes is the mistakes related to classification. Classifications are one of the most important stages of concept development. Through classifications, many objects are combined in common groups and expressed by assigning a common name (term). Thus, the mind makes sense of all of the object at once rather than understanding each one. In this way, the mind is both less tired and it is possible to learn many things in a short time. But classifications need to be distinguished from each other. One of the most important stages in concept learning is the stage of the separation of concepts (Çepni, Ayas, Akdeniz, Özmen, Yiğit \& Ayvacı, 2005).

The fact that, if a student states that an example is in a different group may be an indicator of the student's inability to distinguish between concepts. For this reason, in the fourth type of mistakes, it is necessary to give place to the schemes, concept networks, concept maps, and modelling (5th feedback technique) that will distinguish the concepts from each other and to provide a better interrelation of the concepts (6th feedback technique). In this sense, it is considered that it would be more appropriate to guide the fourth type of mistakes with the fifth and sixth type feedback techniques. Description and definition reminding (saying the answer is wrong) feedback technique can be used to 
indicate that the mistakes do not fit into that group. However, it is thought that students should be allowed to criticize and correct their answers. All teachers in the study specifically gave students on the board a chance to correct their mistake. It has been observed that teachers try all possible methods to avoid putting students in place without getting the correct answer. Teachers have stated that the reason for these efforts is not to break students' self-confidence. These efforts sometimes come to a point where teachers can approach the student on the board and say the correct answer in a way that other students will not hear. The researcher believes that such practices of teachers are pedagogically correct. It is known that self-confidence is an important factor in the upbringing of the individual, that the importance given by teachers to self-confidence in the feedback given to students is effective, and that the importance given to self-confidence varies from community to community (Santagata, 2002, 2004). The researcher thinks that this application, which is done at the expense of telling the answer to the student, maybe a specific application to Turkish school culture.

\section{Conclusion and Recommendations}

Some of the results from this study, which examined that which type of feedback technique was used in which type of mistake, obtained by classifying the mistakes and the given feedbacks encountered by the four mathematics teachers in their lesson are as follows.

Almost any feedback technique can be used in each type of mistake. However, since the first type of mistakes is the product of forgetting, it is seen that the feedback techniques, which include reminding and giving direct information, are used in these mistakes. In other words, it is seen that the use of the first three feedback techniques in the first type of mistakes is more appropriate for this type of mistake than the other mistakes.

In the second type of mistake, it is observed that most "saying the answer is wrong" and then "saying the true answer" is used. Also, the type of mistake that the technique of "creating cognitive disequilibrium" is mostly used for is the second type of mistake.

In the third type of mistake, it is seen that the 2nd, 1st, 3rd, 5th, 4th and 6 feedback techniques are used respectively, however, the associating feedback technique is used once.

In the fourth type of mistake, it is seen that the 3rd, 2nd, 1st and 4th feedback techniques are used mostly and the 5th feedback technique is used once and the 6th feedback technique is used twice.

Teachers do not use the fourth, fifth and sixth feedback techniques adequately. 
The "creating cognitive disequilibrium" feedback technique was found to be a difficult feedback technique to understand, perhaps due to the students' cognitive development at the 7 th grade. However, considering the importance of mathematics education, it was concluded that the rate and amount of use of this conversion technique were insufficient.

The feedback techniques used by teachers are not sufficient when considering the general goals of mathematics.

Teachers have not received any training on mistake, feedback given to mistake and misconceptions.

Although teachers have a viewpoint on the mistake and the feedback given to mistake and talk about the existence of the mistake and its positive or negative effects on learning, it is seen that their perspectives regarding the nature of the mistake, its existence and its role in learning are both very theoretical and inadequate.

In general, when the results are evaluated, it can be seen that the feedback given to the mistakes could not be sufficient level due to the lack of teachers' information about what kind of feedback should be given to the mistakes.

\section{Suggestions}

- The changes of the feedback used can be examined depending on the subjects.

- The feedback given to the mistake and its effects on the student can be investigated by taking into account the place where the mistake occurs (notebook, board, verbally expressed).

- The relationship between teachers' perspectives on mistake and their practices can be examined in more detail, for example through action research.

- The distribution of feedback techniques and mistakes they encounter for the same teachers at different grade levels can be examined and revealed whether there is change.

- Teaching content related to mistake types and feedback techniques can be prepared and taught as a course at the undergraduate level.

- In-service training activities involving mistake types and feedback techniques can be arranged for teachers.

- In order to enrich the feedback techniques used to give feedback to the student who has done a mistake, experts can develop new feedback techniques by examining teaching 
strategies, techniques and methods to eliminate misconceptions.

- When the general goals of mathematics are taken into account, the feedback techniques used by teachers are not sufficient. In-service courses for teachers should be organised to increase the competencies regarding feedback. These courses can be video-based.

- Teachers should not hesitate to use feedback styles, the benefits of which will arise much later, such as creating cognitive disequilibrium.

- Teachers can criticize their approach by examining which feedback technique they use frequently in which type of mistake. It seems that it will not be very effective to make efforts to give high-level feedback especially in the first type of mistake. It may be more appropriate for them to devote time to feedback for other types of mistakes than to spend time using the fourth, fifth and sixth feedback techniques on these types of mistakes.

Acknowledgement

This study is part of the first author's doctoral dissertation named "Anatomy of Mistake: The Mistakes Made by Students in Primary Classes and Analytical Analysis of Teachers' Feedbacks".

The data used in this study was confirmed by the researchers that it belongs to the years before 2020.

Author Contribution Statement

Ali TÜRKDOĞAN: Conceptualization, design of the work, literature search, data analysis, data interpretation, writing-review and editing.

Adnan BAKI: Conceptualization, methodology, consulting and auditing (data analysis, presentation, etc.), editing a review.

\section{References}

Baki, A., (2008). Kuramdan uygulamaya matematik eğitimi [Mathematics education from theory to practice] Harf Eğitim Yayınlarl, Ankara.

Bahar, M., (2002). Students' learning difficulties in biology: reasons and solutions, Kastamonu Education Journal, 10, 73-82.

Bybee, R. W. \& Sound, R. B., (1990). Piaget for educators (Second Edition), Waveland Pres, Inc. Illinois.

Çepni, S., Ayas, A., Akdeniz, A.R., Özmen, H., Yiğit, N. \& Ayvacı, H.Ş., (2005). Kuramdan uygulamaya fen ve teknoloji öğretimi, 4. baskı [Teaching science and technology from theory to practice, 4. printing], Ankara: PegemA Yayıncllık, 
Heinze, A., (2005). Mistake-handling activities in the mathematics classroom, Psychology of Mathematics Education, 3, 105-112.

Nordstrom, C.R., Wendland, D. \& Williams, K. B., (1998). “To err is human”: an examination of the effectiveness of error management training, Journal of Business and Pschology, 12 (3), 269-282.

Santagata, R., (2002). When student make mistake: socialization practices in Italy and the United States, Doctoral Dissertation, Los Angelels: University of California, Philosophy in Psychology.

Sterponi, L. \& Santagata, R., (2000). Mistake in the classroom and at the dinner table: a comparison between socialization practices in italy and the united states, Crossroads of Language, Interaction, and Culture, 3, 57-72.

Türkdoğan, A. (2006). BDMÖ yoluyla sınıf öğretmeni adaylarının denklemler ve grafikleri konusundaki öğrenme ürünlerinin incelenmesi, [Pre service classroom teachers learning out puts' investigations about equations and its graphics via the CBMT]. Yayımlanmamiş Yüksek Lisans Tezi, Karadeniz Teknik Üniversitesi, Fen Bilimleri Enstitüsü, Trabzon.

Türkdoğan, A. (2011). Yanlışın anatomisi: ilköğretim matematik sınıflarında öğrencilerin yaptıkları yanlışlar ve öğretmenlerin dönütlerinin analitik incelenmesi, [The anatomy of mistake: analytical investigation of students' mistakes teachers' feedbacks in the middle school mathematic classes] Yayımlanmamış Doktora Tezi, Karadeniz Teknik Üniversitesi, Eğitim Bilimleri Enstitüsü, Trabzon.

Türkdoğan, A., Baki, A. \& Çepni, S. (2009). The anatomy of mistakes: categorizing students' mistakes in mathematics within learning theories, Turkish Journal of Computer and Mathematics Education, 1(1), 13-26

Türkdoğan, A. \& Baki, A. (2012). İlköğretim ikinci kademe matematik öğretmenlerinin yanlışlara dönüt vermede kullandıkları dönüt teknikleri. [Primary school second grade mathematic teachers' feedback strategies to students' mistakes]. Ankara Üniversitesi Ĕ̆itim Bilimleri Fakültesi Dergisi, 45(2), 157-182.

Türkdoğan, A., \& Baki, A., (2013). Yanlış türleri: ilköğretim ikinci kademe öğrencilerinin yanlışlarının sınıflandırılması. [Classification of middle school students' mistakes: mistake types] Ankara Üniversitesi Eğitim Bilimleri Fakültesi Dergisi, 46(1), 67-88. DOI: 10.1501/Egifak_0000001274

Vygotsky, L. S, (1978). Mind in society: the developmental of higher psychological processes, Cambridge Massachusetts. London, Harvard University Press, England.

Vygotsky, L. S. (1986). Thoughts and language. Cambridge, , MA: Harvard University Press.

Wood, D., Bruner, J. \& Ross, G., (1976). The role of tutoring in problem solving, Journal of Child Psychology and Psychiatry, 17, 89-100. 